\title{
Pandemic (H1N1) 2009 virus outbreak in a school in London, April-May 2009: an observational study
}

\author{
L. CALATAYUD ${ }^{1,2}$, S. KURKELA ${ }^{2,3}$, P. E. NEAVE ${ }^{4}$, A. BROCK ${ }^{4}$, S. PERKINS ${ }^{4}$, \\ M. ZUCKERMAN ${ }^{5}$, M. SUDHANVA ${ }^{5}$, A. BERMINGHAM ${ }^{2}$, J. ELLIS $^{2}$, \\ R. PEBODY ${ }^{2}$, M. CATCHPOLE ${ }^{2}$, R. HEATHCOCK ${ }^{4}$ AND H. MAGUIRE ${ }^{6 *}$ \\ ${ }^{1}$ European Programme for Intervention Epidemiology Training (EPIET), European Centre for Disease Control, \\ Stockholm, Sweden \\ ${ }^{2}$ Health Protection Agency, Centre for Infections, London, UK \\ ${ }^{3}$ European Public Health Microbiology Training Programme (EUPHEM), European Centre for Disease \\ Control, Stockholm, Sweden \\ ${ }^{4}$ South-East London Health Protection Unit, London, UK \\ ${ }^{5}$ Health Protection Agency, London Regional Laboratory, Kings College Hospital NHS Foundation Trust, \\ London, UK \\ ${ }^{6}$ Health Protection Agency, Regional Epidemiology Unit, London, UK
}

(Accepted 28 October 2009; first published online 20 November 2009)

\section{SUMMARY}

On 29 April 2009, an imported case of pandemic (H1N1) 2009 virus infection was detected in a London school. As further cases, pupils and staff members were identified, school closure and mass prophylaxis were implemented. An observational descriptive study was conducted to provide an insight into the clinical presentation and transmission dynamics in this setting. Between 15 April and 15 May 2009, 91 symptomatic cases were identified: 33 were confirmed positive for pandemic (H1N1) 2009 virus infection; 57 were tested negative; in one the results were unavailable. Transmission occurred first within the school, and subsequently outside. Attack rates were $2 \%$ in pupils (15\% in the $11-12$ years age group) and $17 \%$ in household contacts. The predominant symptoms were fever $(97 \%)$, respiratory symptoms $(91 \%)$, and sore throat $(79 \%)$. Limited spread in the school may have been due to a combination of school closure and mass prophylaxis. However, transmission continued through household contacts to other schools.

Key words: Infection control, infection transmission, outbreaks, respiratory infections, swine-origin influenza A H1N1 virus.

\section{INTRODUCTION}

The first cases of the current global outbreak of pandemic (H1N1) 2009 virus infection were observed in Mexico and the USA in late April 2009 [1, 2]. Since 1 July 2009, 70893 cases have been reported

\footnotetext{
* Author for correspondence: Dr H. Maguire Health Protection Agency, Regional Epidemiology Unit, 7th Floor, Holborn Gate, 330 High Holborn, WC1V 7PP London, UK.

(Email: helen.maguire@hpa.org.uk)
}

worldwide, including 311 deaths [3]. In the UK, the first confirmed cases were reported on 27 April, and there were a total of 65 cases detected during the period 27 April to 11 May [4]. The first reports suggested that pandemic (H1N1) 2009 virus infections mainly affect young people and younger adults, and the infection spreads within households [4].

Children are effective in spreading influenza virus [5]. During seasonal influenza epidemics children are often the first to be affected [5], and especially 
school-aged children have high infection rates [6]. Schools provide a favourable environment for influenza transmission [7], and outbreaks in schools occur frequently. Moreover, a notable proportion of household transmission has been attributed to children [8]. Since the beginning of the currently ongoing pandemic, several school outbreaks have been reported around the world $[9,10]$.

One of the local Health Protection Units (HPU) in London was alerted on 29 April to potential cases of pandemic (H1N1) 2009 virus in a mixed school of 1177 pupils in London. Investigations confirmed that this was the first school outbreak with more than one case in the UK. General infection control practices and good respiratory and hand hygiene, as well as self-isolation advice were promulgated widely within the school. The school was closed during Easter (15-20 April) and from 2 to 10 May. Mass antiviral prophylaxis was distributed to pupils and staff on 4 and 5 May.

The aim of this investigation was to analyse and describe in detail the nature and extent of this outbreak in order to inform the management of this and other school outbreaks. We also consider the potential contribution of clinically ill individuals who failed to be confirmed as cases, but whose illness may have been caused by pandemic (H1N1) 2009 virus. The rationale for including these individuals was the limited information available on the performance of the laboratory testing procedures at the time of the investigation, as well as possible reduced viral shedding after antiviral prophylaxis.

\section{METHODS}

An observational descriptive study was carried out to describe the outbreak and connections between cases, and to present them using social mixing maps in spider diagrams. Data sources included questionnaires completed for each case. These were carried out as part of the First Few Hundred (FF100) project in the UK. This was implemented to collect key clinical, epidemiological, and virological information about the earliest laboratory-confirmed cases of pandemic (H1N1) 2009 virus [11]. Active searching and followup of the cases and their close contacts was undertaken by the HPUs and Health Protection Agency, Centre for Infections. The study population included any individual who attended the school as a pupil or worked there as a staff member between 15 April and 15 May and their close contacts. A close contact, in accordance with the UK national guidelines at the time was defined as: any individual who lived in the same household as the case; or who provided informal care to the case, coming within speaking distance $(<1 \mathrm{~m})$; or exposed to a case at a distance of $<1 \mathrm{~m}$ with continuous exposure for $>1 \mathrm{~h}$; or any healthcare or social-care worker who provided direct clinical or personal care or who examined a symptomatic case. A 'confirmed' case (C) was tested positive for pandemic (H1N1) 2009 virus RNA; a 'possible' case (P) was symptomatic with one of a set of symptoms compatible with an influenza-like illness and from whom a combined nose and throat swab could not be collected but serological test results were pending; and a 'symptomatic-negative' case (S) was symptomatic with one of a set of influenza-like illness symptoms but tested negative for influenza $\mathrm{A}$ or pandemic (H1N1) 2009 virus RNA. The cases had different associations to the school which were defined as: pupil, teaching staff member, non-teaching staff member [including health-care workers (HCWs) in the school], household contact, HCW outside the school, and social contact. Combined nose and throat swabs were collected from all individuals with symptoms, and tested by real-time polymerase chain reaction for influenza A and B virus RNA. Samples in which influenza A virus RNA was detected were then subtyped in order to determine whether the influenza $\mathrm{A}$ was seasonal influenza subtype $\mathrm{H} 1$ or $\mathrm{H} 3$. If the virus was untypable, the sample was referred to confirmation as pandemic (H1N1) 2009 virus RNA by nucleotide sequence analysis.

\section{RESULTS}

A total of 33 confirmed, one possible and 57 symptomatic-negative cases having an association with the school were identified between 15 April and 15 May. Confirmed cases became ill between 25 April and 5 May. The attack rate of confirmed cases in pupils was $2 \%(3 \%$ in boys and $1 \%$ in girls $)$ and in staff members $0.45 \%$. The first confirmed case $(\mathrm{C} 4$, with onset on 25 April) was a Year 7 pupil aged 11 who had travelled abroad in risk areas and who, after returning to the UK, attended school from 21 to 24 April.

The only two staff members who became confirmed cases were staff who had cared for pupils who were ill at school. There were no confirmed cases in the teaching staff. The first case associated with the school (P1) was a Year 7 pupil aged 13 who had travelled in 


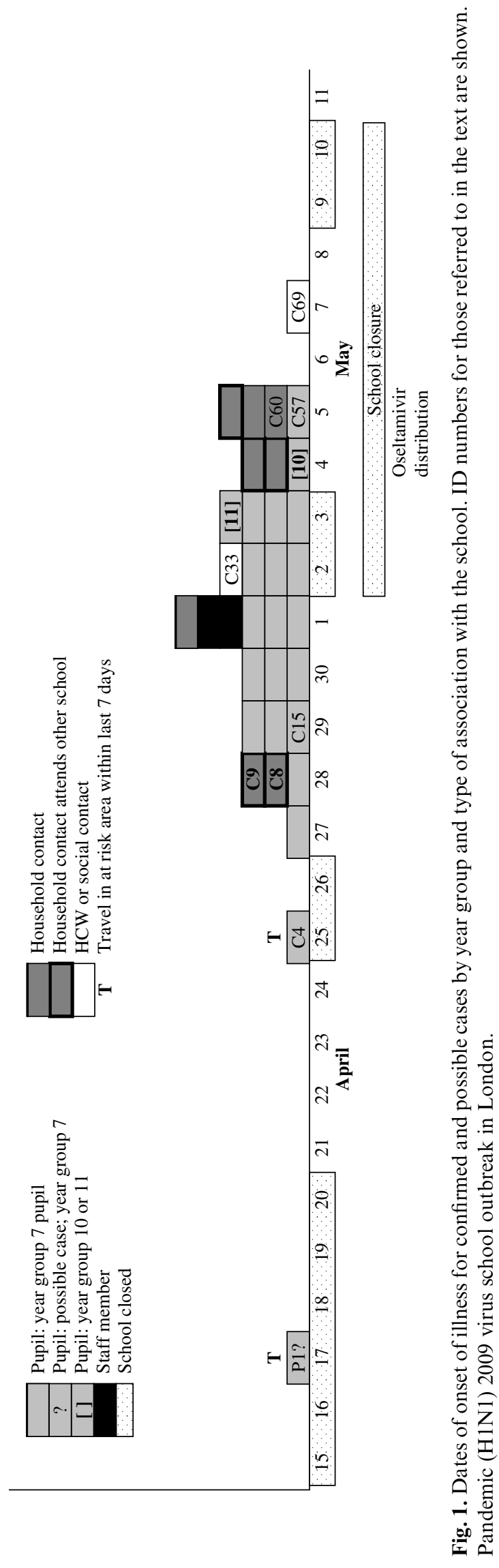

risk areas in April. P1 was unwell upon returning to the UK and went back to school without symptoms. P1 remains a possible case, as it was too late to acquire a respiratory swab at the time of detection. In addition to $\mathrm{C} 4$ and $\mathrm{P} 1$, only one other case had a recent travel history outside the UK (dates unknown).

The school was divided into junior (year groups Reception to 6) and senior school (year groups 7-13) with 69 classes, and 1177 pupils. Classrooms of year groups 7 and 8 were housed in a two-storey Lower school building separate from other year groups. There was mixing of year groups 7-11 during lunch periods. There were 444 staff members; 158 teaching staff, and 286 non-teaching staff members of whom some were working part-time.

Year group 7 (aged 11-12) was the most affected with an attack rate of $15 \%$. This year group had five classes with the following attack rates: $24 \%, 20 \%$, $13 \%, 12 \%$, and $8 \%$. The four classes with rates $>10 \%$ were all on the upper floor of the Lower school building. Only two other year groups (10 and 11) were affected, and with a low attack rate ( $1 \%$ for both).

The epidemic curve suggests person-to-person transmission starting inside the school (Fig. 1), first affecting year group 7, thereafter moving on to other year groups (10 and 11), and finally with secondary transmission outside the school (Fig. 1). The attack rate for confirmed cases in all close contacts was $11 \%$ and that of household contacts $17 \%$. There were four families where secondary transmission occurred from pupils. The epidemic curve including both confirmed, possible, and symptomatic-negative cases (data not shown) had a similar shape as for confirmed cases only, and shared the same peak (1 May).

The predominant symptoms (Table 1) were fever $(97 \%)$, respiratory symptoms $(91 \%)$, and sore throat $(79 \%)$, with over one third of younger cases (aged $<18$ years) reporting diarrhoea or vomiting. All symptoms presented in Table 1 were significantly more frequent in the confirmed cases. No significant difference was found between age groups $<18$ years and $\geqslant 18$ years, except for sneezing which was more frequent in the latter. None of the confirmed cases were hospitalized.

A total of 90 individuals (33 confirmed, 57 symptomatic-negative) were swabbed, and 32 (16 confirmed, 16 symptomatic-negative) received oseltamivir before being swabbed (interval data available only for 70 individuals of the 90 swabbed). The average interval from onset of symptoms to swabbing was fairly short: range $0-10$, median 3 days ( 3 days for 
Table 1. Symptoms of cases by age group and case status*. Statistical testing for comparison of age groups was done by Fisher's exact test and case status groups by $\chi^{2}$ test. Pandemic (H1N1) 2009 virus school outbreak in London

\begin{tabular}{|c|c|c|c|c|c|c|c|c|c|c|}
\hline & \multicolumn{2}{|c|}{$\begin{array}{l}\text { Age group } \\
<18 \text { yr, } \\
\text { confirmed cases }\end{array}$} & \multicolumn{2}{|c|}{$\begin{array}{l}\text { Age group } \\
\geqslant 18 \mathrm{yr}, \\
\text { confirmed cases }\end{array}$} & \multirow{2}{*}{$\begin{array}{l}P \\
\text { value }\end{array}$} & \multicolumn{2}{|c|}{$\begin{array}{l}\text { Total, } \\
\text { confirmed } \\
\text { cases }\end{array}$} & \multicolumn{2}{|c|}{$\begin{array}{l}\text { Total, } \\
\text { symptomatic } \\
\text { negative cases }\end{array}$} & \multirow{2}{*}{$\begin{array}{l}P \\
\text { value }\end{array}$} \\
\hline & $n$ & $\%$ & $n$ & $\%$ & & $n$ & $\%$ & $n$ & $\%$ & \\
\hline Fever & 25 & 96 & 7 & 100 & n.s. & 32 & 97 & 44 & 81 & $0 \cdot 02$ \\
\hline $\begin{array}{c}\text { Respiratory } \\
\text { symptoms }\end{array}$ & 23 & 88 & 7 & 100 & n.s. & 30 & 91 & 28 & 50 & $<0 \cdot 01$ \\
\hline Headache & 21 & 81 & 6 & 86 & n.s. & 27 & 82 & 21 & 37 & $<0.01$ \\
\hline Sore throat & 20 & 77 & 6 & 86 & n.s. & 26 & 79 & 31 & 56 & 0.03 \\
\hline Fatigue & 18 & 69 & 6 & 86 & n.s. & 24 & 73 & 5 & 9 & $<0 \cdot 01$ \\
\hline Loss of appetite & 18 & 69 & 4 & 57 & n.s. & 22 & 66 & 1 & 3 & $<0.01$ \\
\hline Chills & 16 & 62 & 3 & 43 & n.s. & 19 & 58 & 4 & 14 & $<0.01$ \\
\hline Rhinorrhoea & 14 & 54 & 5 & 71 & n.s. & 19 & 58 & 15 & 26 & $<0.01$ \\
\hline Cough & 14 & 54 & 6 & 86 & n.s. & 20 & 61 & 12 & 22 & $<0.01$ \\
\hline Myalgia & 14 & 54 & 5 & 71 & n.s. & 19 & 58 & 5 & 9 & $<0.01$ \\
\hline Arthralgia & 11 & 42 & 5 & 71 & n.s. & 16 & 48 & 3 & 5 & $<0.01$ \\
\hline $\begin{array}{l}\text { Diarrhoea/ } \\
\text { vomiting }\end{array}$ & 10 & 38 & 1 & 14 & n.s. & 11 & 33 & 4 & 7 & $<0 \cdot 01$ \\
\hline Nausea & 8 & 31 & 2 & 29 & n.s. & 10 & 31 & 3 & 5 & $<0.01$ \\
\hline Sneezing & 6 & 23 & 5 & 71 & $0 \cdot 03$ & 11 & 33 & n.a. & - & $<0 \cdot 01$ \\
\hline
\end{tabular}

n.s., Not significant; n.a., not available.

* The following clinical manifestations were reported only rarely by cases, and are not shown in the table: dizziness, conjunctivitis, confusion, shortness of breath, general malaise, blurry vision, stomach pain, nose bleed, and rash.

confirmed, 2 days for symptomatic-negative cases) (Fig. 2). Four cases were swabbed twice as the first swab result was negative; for two of them the second test was positive.

Oseltamivir was offered to $97 \%$ of the confirmed cases and of $88 \%$ of the symptomatic-negative. One confirmed case and 10 symptomatic-negative cases received oseltamivir before presenting with symptoms. The median delay between onset of symptoms and receiving oseltamivir was 2 days (Fig. 2). Of the confirmed cases, 11 attended the school on the day of their illness onset; and two were at school for more than 1 day while symptomatic (Fig. 2), before it was known that their illness was due to pandemic (H1N1) 2009 virus infection. None of these children had received oseltamivir prior to the onset of their symptoms.

Figure 3 shows the 21 confirmed cases in pupils in the school according to the date of onset of symptoms. C4 was an imported case and of the 20 further cases, 15 had contact in school with another confirmed case; the number of prior contacts ranged from 1 to 5 . For five cases, no prior clear contact within the school could be determined. Of the 21 confirmed cases
(Fig. 3), the number of possible onward transmissions ranged from 0 to 6 . Delay between last contact and onset of symptoms varied from 1 to 8 days. The contribution of other potential intermediary cases along the chain of transmission cannot be established and thus the upper limit of the incubation period cannot be estimated.

Available data allowed linking of all confirmed cases either through a direct contact with another case (confirmed or symptomatic-negative); through links from asymptomatic individuals to their confirmed sibling cases in other classes; or links to events where there were associated cases. Figure 4 shows the five classes in year group 7 in the centre with their affiliated cases, as well as the link between them and other asymptomatic individuals in other classes, e.g. year groups 10 and 11. All those classes or year groups featuring confirmed or symptomatic-negative cases could be linked with each other. There were asymptomatic siblings of confirmed cases from year group 7 in year groups 10 and 11 (C51 and C42).

A total of eight confirmed cases occurred in household contacts. For one of these cases, the only link to the school is through a symptomatic-negative case. 


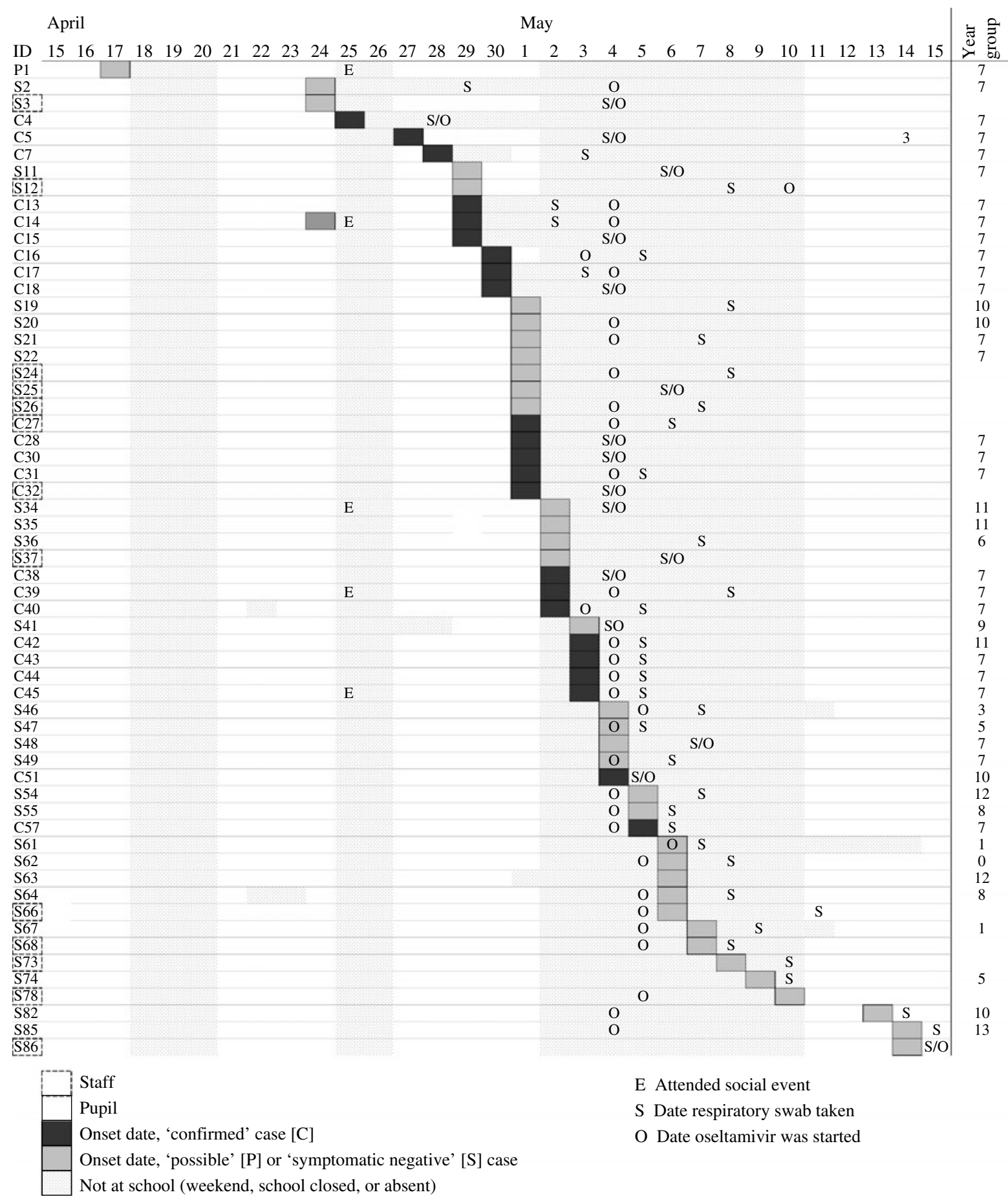

Fig. 2. Onset of symptoms, swabbing date, date oseltamivir was started, and absence from school for confirmed, possible, and symptomatic-negative cases who attended the school as a pupil or a staff member. For those with two swabs, the first date of swabbing is shown. Pandemic (H1N1) 2009 virus school outbreak in London.

Secondary transmission occurred through four pupils (C4, C39, C15, and C38) to households (Fig. 4). Five confirmed cases, siblings of pupils, attended four other schools in London (Fig. 1). In two of these schools, confirmed tertiary cases were subsequently identified (Fig. 4); the transmissions occurred from $\mathrm{C} 4$ to $\mathrm{C} 8$ and $\mathrm{C} 9$ (School X), and from C39 to C58 (School Y).

There were three contacts that provided direct health care to confirmed cases and became confirmed 


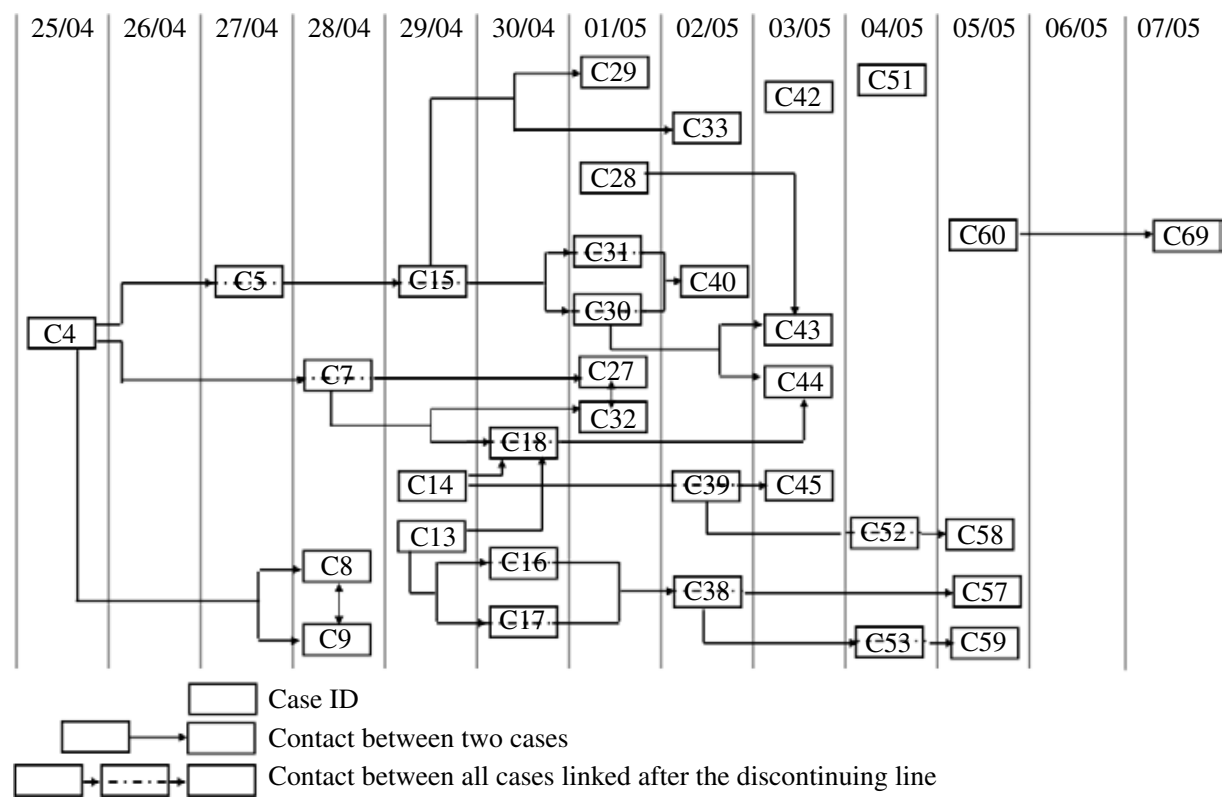

Fig. 3. Spider diagram showing contacts between confirmed cases by onset of symptoms. Pandemic (H1N1) 2009 virus school outbreak in London.

as cases (Fig. 4). There was also a further such individual (S86) who was symptomatic and had contact with confirmed cases, but was found on testing to be pandemic (H1N1) 2009 virus-negative.

Investigations suggest the possibility that further secondary and tertiary transmission of pandemic (H1N1) 2009 virus may have taken place during a social event on 25 April. This event was attended by 27 children, of whom 18 were also from year group 7, and one from year group 11. Three participants (C14, C39, C45) who were also classmates became confirmed as cases with illness onsets on 29 April, 2 May and 3 May, respectively. Of note, the possible case P1 attended the party, but had already recovered at this time.

\section{DISCUSSION}

In this report we describe the first school outbreak involving more than one case of pandemic $(\mathrm{H} 1 \mathrm{~N} 1)$ 2009 virus infection in the UK. The index case in this outbreak was an imported case returning from a risk area. Virus transmission occurred both inside the school, and subsequently in households and healthcare workers. Notably, transmission to two other schools occurred due to onward transmission through siblings of the school pupils. Mass antiviral prophylaxis and school closure may have contributed to containment of the outbreak.
There are a number of limitations in this investigation in terms of quality and completeness of the data available. Different sources were combined to obtain data. For the confirmed cases, a questionnaire with closed questions was used, whereas for the symptomatic-negative cases, data were collected from several sources, containing more open questions. Comparison of confirmed and symptomatic-negative cases is therefore difficult. In addition, parents provided the information for their children. This may have influenced the reliability of the data. For some individuals only very few data were available about social contacts.

In our investigation, samples from two confirmed cases were first tested negative. The discrepancies might be due to several factors, which include timing of sampling, sampling procedure under field conditions, and sample transportation. Of note, a total of 32 individuals (16 confirmed, 16 symptomaticnegative) received oseltamivir before being swabbed, which may have resulted in reduced viral shedding.

The predominant clinical symptoms described in an earlier study [12] are in line with our results for confirmed cases. However, we show a lower hospitalization rate, which might be due to different study populations in terms of age distribution and underlying medical conditions. Some of the differences between the clinical picture of confirmed and symptomatic-negative cases may be explained by use 


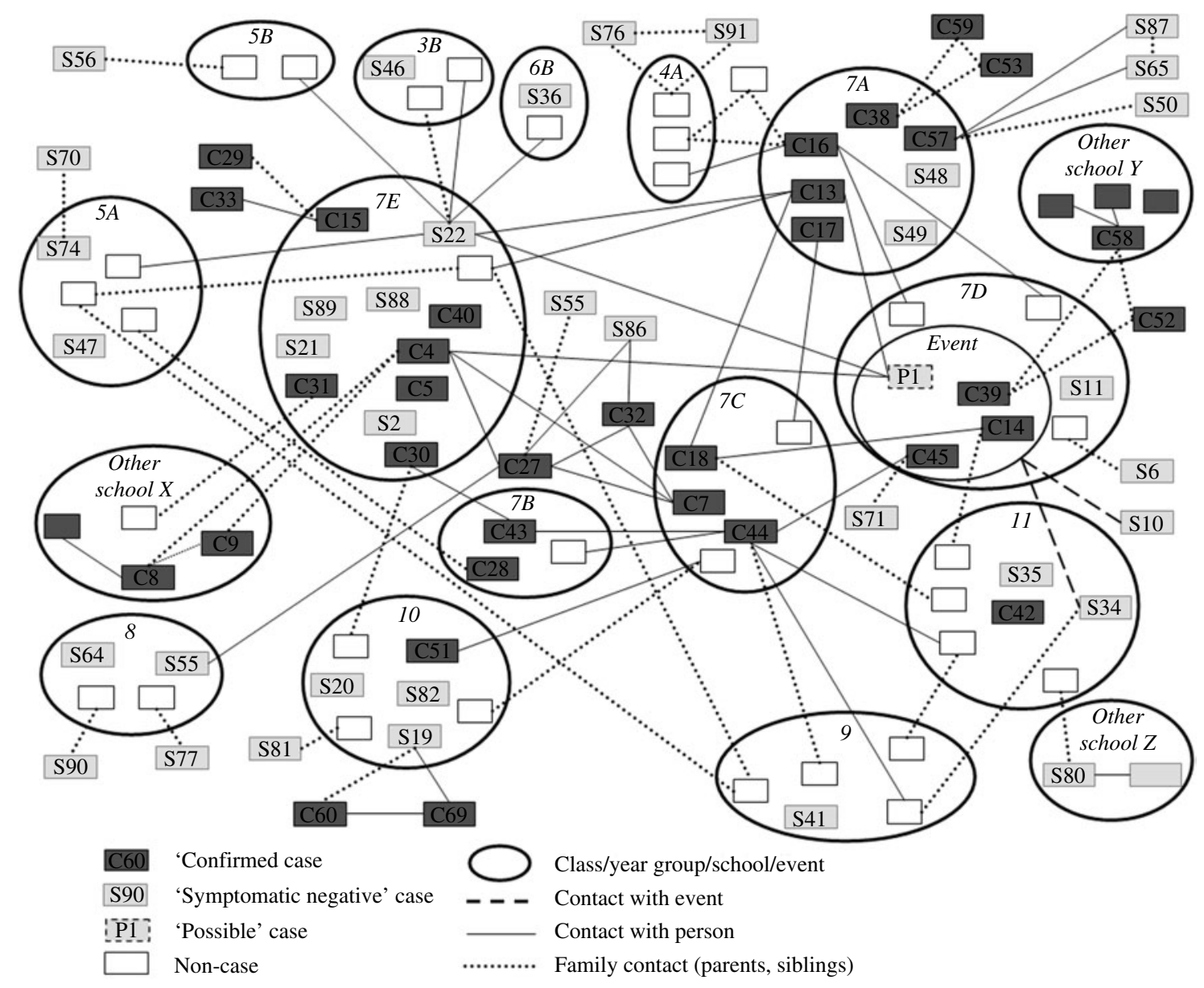

Fig. 4. Spider diagram representing known close contacts between confirmed, possible, and symptomatic-negative cases, as well as non-cases that may play role in the transmission events. The ellipses indicate the respective group or event that the individuals share. Known contacts inside a group representing, e.g. a class, are not presented. Further, an event, taking place on 25 April, is not fully detailed in the interests of clarity; however, the confirmed cases and possible case P1 that did attend this party are shown in the ellipse. Pandemic (H1N1) 2009 virus school outbreak in London.

of different data sources for these groups, as well as increased clinical alertness towards the end of the outbreak when most symptomatic-negative cases were detected.

Previous studies suggest that the majority of the contacts for school-aged children are with their peers, which may explain quick spread of influenza through certain year groups [13]. In this London school, one year group was almost exclusively affected. Further, the only staff members who became confirmed cases had cared for pupils who were ill, and no confirmed cases occurred in other staff members who had not had such close contact with ill pupils. This suggests that transmission of pandemic (H1N1) 2009 virus requires close contact, which is also supported by studies on seasonal influenza [14].
Asymptomatic individuals may have played a role in transmission events in this school setting; however, this study did not consider the role of random contacts and there may be considerable underreporting in contacts. Studies on social contact networks of teenagers and children suggests that the highest risk for transmission are in households, school classes, sports, public activity events and through friends, whereas random contacts can be numerous but have lower transmission potential [13].

In this outbreak, transmission occurred in four families. Evidence suggests that shedding of influenza virus is more frequent in children than in adults [15] and transmission of influenza from adolescents to adults occurs more frequently than vice versa [16]. Even if children and teenagers are a minority of the 
total population, they are responsible for the majority of transmission events [16].

Several confirmed cases attended the school while symptomatic but before realizing their illness was due to pandemic (H1N1) 2009 virus, which may have enabled enhanced transmission inside the school before public health measures could be put in place. This and other school outbreaks have shown the difficulty in administration of antiviral prophylaxis in a timely way [17]; the delay in this outbreak from first notification of a suspected case at the school to the administration of antiviral prophylaxis was 5 days. Limited spread at the school seems to be explicable by the fact that the Lower school is quite separate from the main school as well as by the combined effects of school closure and antiviral prophylaxis of all school pupils. Due to the fact the two public health interventions coincided, it is difficult to assess the true impact of either of them. It is notable that there was no evidence of community transmission of pandemic (H1N1) 2009 virus in London at the time. Our limited data suggest that oseltamivir may have played a role in preventing transmission. After prophylaxis was issued just one confirmed case became ill but there were 10 symptomatic-negative cases. Modelling studies have shown that school closure could be effective at containing transmission in adolescents; however, it could also result in increasing household contacts and outside school activities [13]. This is also supported by studies carried out with seasonal influenza [7].

Schools need to be prepared for pandemic influenza before they open after the summer break. Prompt notification of cases is important to allow early detection of school outbreaks and implementation of public health measures. There are existing pandemic influenza plans that schools should activate. These plans should include advice to teachers and affiliated health-care professionals on the use of face masks and or personal protective equipment, on establishment of coherent triage systems and side-rooms to cohort infected students. Furthermore, schools need to be prepared to swiftly communicate clear respiratory and hand hygiene and self-isolation to pupils and parents, through, e.g. posters and the internet. Materials should include expected scenarios and how to deal with them. Further work is needed to better define conditions under which the pandemic (H1N1) 2009 virus may transmit in a school setting and households, including comparison of school outbreaks, modelling of contacts, and assessing the possible role of asymptomatic transmission.

\section{ACKNOWLEDGEMENTS}

The authors would like to thank Professor David Brown, Ms. Charlotte Ingram, Dr Paul Crook, all staff at South East and South West London Health Protection Units, and the staff and pupils at the affected school. We thank Dr Brian McCloskey and Dr Viviane Bremer for helpful comments on the manuscript. S.K. is affiliated as a Fellow in the EUPHEM programme, which is developed and endorsed by Establishment of a Collaborative Network of European Laboratories for Outbreak Assistance and Support co-ordinated by the European Network for Diagnostics of 'Imported' Viral Diseases (ENIVD-CLRN) and the ECDC.

\section{DECLARATION OF INTEREST}

None.

\section{REFERENCES}

1. Charatan F. UN warns that swine flu outbreak could turn into pandemic. British Medical Journal 2009; 338: b1751.

2. Cohen J. Swine flu outbreak. Out of Mexico? Scientists ponder swine flu's origin. Science 2009; 324: 700-702.

3. World Health Organization. Influenza $A(H 1 N 1)$ Update 55 (29 June). (www.who.int). Accessed 1 July 2009.

4. Health Protection Agency and Health Protection Scotland Influenza virus A(H1N1) Investigation Teams. Epidemiology of influenza virus $\mathrm{A}(\mathrm{H} 1 \mathrm{~N} 1) \mathrm{v}$ in the United Kingdom, April-May 2009. Eurosurveillance 2009; 14(19): pii $=19213$.

5. Monto AS. Interrupting the transmission of respiratory tract infections: theory and practice. Clinical Infectious Diseases 1999; 28: 200-204.

6. Glezen WP, et al. Influenza virus infections in infants. Pediatric Infectious Disease Journal 1997; 16: 1065-1068.

7. Glezen WP. Herd protection against influenza. Journal of Clinical Virology 2006; 37: 237-243.

8. Viboud C, et al. Risk factors of influenza transmission in households. British Journal of General Practice 2004; 54: 684-689.

9. CDC. Swine-Origin Influenza A (H1N1) Virus Infections in a School- New York City, April 2009. Morbidity and Mortality Weekly Reports 2009; 58: 470-472.

10. Anon. Human infection with influenza virus $\mathrm{A}(\mathrm{H} 1 \mathrm{~N} 1)$ : clinical observations from a school-associated outbreak in Kobe, Japan, May 2009. WHO Weekly Epidemiological Record 2009; 24: 237-248.

11. McMenamin $\mathbf{J}$, et al. Minimum dataset for confirmed human cases of influenza H5N1. Lancet 2008; 372: 696-697.

12. Novel Swine-Origin Influenza A (H1N1) investigation Team. Emergence of a novel swine-origin influenza A 
(H1N1) virus in humans. New England Journal of Medicine 2009; 360: 2605-2615.

13. Glass LM, Glass RJ. Social contact networks for the spread of pandemic influenza in children and teenagers. BMC Public Health 2008; 8: 61.

14. Brankston G, et al. Transmission of influenza A in human beings. Lancet Infectious Diseases 2007; 7: 257-265.

15. Neuzil KM, Hohlbein C, Zhu Y. Illness among schoolchildren during influenza season: effect on school absenteeism, parental absenteeism from work, and secondary illness in families. Archives of Pediatric and Adolescent Medicine 2002; 156: 986-991.

16. Glass RJ, et al. Targeted social distancing design for pandemic influenza. Emerging Infectious Diseases 2006; 12: 1671-1681.

17. Wallensten A, et al. Compliance and side effects of prophylactic oseltamivir treatment in a school in South West England. Eurosurveillance 2009 30; 14: 19285. 